\title{
The Oral Antidiabetic Pioglitazone Protects from Neurodegeneration and Amyotrophic Lateral Sclerosis-Like Symptoms in Superoxide Dismutase-G93A Transgenic Mice
}

\author{
Burkhard Schütz, ${ }^{1}$ Jens Reimann, ${ }^{2}$ Lucia Dumitrescu-Ozimek, ${ }^{2}$ Karin Kappes-Horn, ${ }^{2}$ Gary E. Landreth, ${ }^{3}$ \\ Britta Schürmann, ${ }^{1}$ Andreas Zimmer, ${ }^{1}$ and Michael T. Heneka ${ }^{2}$ \\ ${ }^{1}$ Laboratory of Molecular Neurobiology, Department of Psychiatry and Psychotherapy, and ${ }^{2}$ Laboratory of Neuroinflammation, Department of Neurology, \\ University of Bonn, 53127 Bonn, Germany, and ${ }^{3}$ Alzheimer Research Laboratory, Department of Neuroscience, Case Western Reserve University, \\ Cleveland, Ohio 44106-4928
}

\begin{abstract}
Amyotrophic lateral sclerosis (ALS) represents a fatal neurodegenerative disorder characterized by progressive death of the upper and lower motor neurons. Because accompanying inflammation may interact with and promote neurodegeneration, anti-inflammatory treatment strategies are being evaluated. Because peroxisome proliferator-activated receptor $\gamma(\operatorname{PPAR} \gamma)$ agonists act as potent antiinflammatory drugs, we tested whether superoxide dismutase (SOD1)-G93A transgenic mice, a mouse model of ALS, benefit from oral treatment with the PPAR $\gamma$ agonist pioglitazone (Pio). Pio-treated transgenic mice revealed improved muscle strength and body weight, exhibited a delayed disease onset, and survived significantly longer than nontreated SOD1-G93A mice. Quantification of motor neurons of the spinal cord at day 90 revealed complete neuroprotection by Pio, whereas nontreated SOD1-G93A mice had lost 30\% of motor neurons. This was paralleled by preservation of the median fiber diameter of the quadriceps muscle, indicating not only morphological but also functional protection of motor neurons by Pio. Activated microglia were significantly reduced at sites of neurodegeneration in Pio-treated SOD1-G93A mice, as were the protein levels of cyclooxygenase 2 and inducible nitric oxide synthase. Interestingly, mRNA levels of the suppressor of cytokine signaling 1 and 3 genes were increased by Pio, whereas both the mRNA and protein levels of endogenous mouse SOD1 and of transgenic human SOD1 remained unaffected.
\end{abstract}

Key words: motor neurons; degeneration; neuroinflammation; peroxisome proliferator-activated receptor; microglia; glia

\section{Introduction}

Peroxisome proliferator-activated receptor $\gamma(\operatorname{PPAR} \gamma)$ ligands were developed as oral antidiabetic drugs after the discovery that PPAR $\gamma$ activation increases insulin sensitivity and normalizes serum glucose levels (Berger and Moller, 2002). To date, several million non-insulin-dependent diabetes mellitus (NIDDM) patients are taking pioglitazone (Pio; Actos) or rosiglitazone (Avandia) medication daily, both PPAR $\gamma$ activators of the thiazolidinedione (TZD) class of antidiabetic drugs. Beyond their insulin sensitizing and other metabolic actions, PPAR $\gamma$ ligands exert several other PPAR $\gamma$-dependent and -independent antineoplastic and anti-inflammatory effects (Daynes and Jones, 2002; Blanquart et al., 2003; Grommes et al., 2004). Because several neurodegenerative disorders, such as Alzheimer's disease

Received Jan. 16, 2005; revised July 2, 2005; accepted July 5, 2005

The work was supported by grants from the Deutsche Gesellschaft für Muskelkranke to B.S., from the Deutsche Forschungsgemeinschaft to J.R. (Re1547/2-1), to M.T.H. (SFB400/A8), and to A.Z. (SFB400/A11), and by Grant DA016768 from the National Institutes of Health to A.Z. We thank Prof. Fred Nyberg (Uppsala, Sweden) for the generous gift of the CGRP antibody and Dr. Albrecht Clement (Mainz, Germany) for donating SOD1 antibodies.

Correspondence should be addressed to Dr. Michael T. Heneka, Department of Neurology, University of Münster, Albert-Schweitzer-Strasse 33, 48149 Münster, Germany. E-mail: heneka@uni-muenster.de.

B. Schütz's present address: Laboratory on Molecular Neurosciences, Institute of Anatomy and Cell Biology, University of Marburg, 35037 Marburg, Germany.

DOI:10.1523/JNEUROSCI.2038-05.2005

Copyright $\odot 2005$ Society for Neuroscience $\quad$ 0270-6474/05/257805-08\$15.00/0
(AD) and amyotrophic lateral sclerosis (ALS), are accompanied by an inflammatory component, it has been hypothesized that both neuroinflammatory and neurodegenerative mechanisms mutually interact (Akiyama et al., 2000; Weydt et al., 2002). Based on this hypothesis, anti-inflammatory treatment strategies are being developed and tested in animal models and clinical trials of ALS and AD (Lim et al., 2000; In t'Veld et al., 2001; Drachman et al., 2002; Pompl et al., 2003).

The primary pathological feature of ALS is the loss of motor neurons (Talbot, 2002), which is accompanied by a robust glial response including activation of microglia and astrocytes as well as the expression of cyclooxygenase 2 (COX-2) and nitric oxide synthase (iNOS) in the spinal cord (Phul et al., 2000; Almer et al., 2001; Yasojima et al., 2001; Barbeito et al., 2004). Both pathologies, motor neuron loss and neuroinflammation, can be found in transgenic mice overexpressing mutant variants of the human gene encoding for copper/zinc superoxide dismutase (SOD1), which have been linked to inherited ALS (Gurney et al., 1994; Hensley et al., 2002; Yoshihara et al., 2002; Kunst, 2004).

The massive appearance of activated microglia and astrocytes already at an early, presymptomatic stage of disease in SOD1 transgenic mice suggests that inflammation may contribute to motor neuron degeneration and suppression of the inflammatory component could be neuroprotective. In microglia and mac- 
rophages, PPAR $\gamma$ activation results in inhibition of proinflammatory gene expression through various mechanisms (Landreth and Heneka, 2001; Daynes and Jones, 2002; Blanquart et al., 2003). We have demonstrated that PPAR $\gamma$ agonists reduce amyloid $\beta$ peptide and cytokine mediated neuroinflammation and neurotoxicity in vitro (Heneka et al., 1999; Combs et al., 2000) and in vivo (Heneka et al., 2000).

Given the beneficial effects observed in these studies, we tested whether an oral treatment of SOD1 transgenic mice with the $\operatorname{PPAR} \gamma$ agonist pioglitazone would reduce neuroinflammation, protect from motor neuron loss, and improve clinical ALS symptoms.

\section{Materials and Methods}

Animal model. Transgenic mice of the strain B6SJL-TgN(SOD1G93A)1Gur (The Jackson Laboratory, Bar Harbor, ME), which harbor human SOD1 with the G93A mutation in high copy number, were used. Progeny for experimental analysis were obtained from breeding pairs between SOD1-G93A transgenic and C57BL/6 wild-type (wt) mice. Transgenic mice were identified by PCR using primers and a protocol suggested by the vendor. All mice were housed in groups of two to six animals in single ventilated cages on a $12 \mathrm{~h}$ light/dark cycle and ad libitum access to food and water. From the time on when transgenic mice showed motor deficits, food and water were placed on the cage floor. Because of ethical considerations, transgenic animals were killed when their body weight had dropped below $80 \%$ of the weight at the beginning of the experiment. At this end stage of disease, mice showed severe atrophy of limb and body wall muscles and were unable to move, eat, and drink. Animal care and handling was performed according to the declaration of Helsinki and approved by local ethical committees.

Pioglitazone treatment. Male wild-type $(n=35)$ and transgenic $(n=$ 35 ) mice were used and divided into Pio-treated ( $n=18$ for wt; $n=13$ for SOD1) and nontreated ( $n=17$ for wt; $n=22$ for SOD1) groups. Because the heterogeneous genetic background of the study mice results in significantly different survival times between males and females (Heiman-Patterson et al., 2003), male mice were used in all experiments. In the present experiment, mice were fed Purina 5002 (Purina Mills, St. Louis, MO) rodent chow ad libitum, supplemented with 240 ppm pioglitazone (ActosTM; Takeda Pharmaceuticals, Osaka, Japan). The latter drug concentration was chosen because only $18 \%$ of pioglitazone crosses the blood-brain barrier in mammals as described in detail by others (Maeshiba et al., 1997). The final dosage of drug was computed to be 40 $\mathrm{mg} \cdot \mathrm{kg}^{-1} \cdot \mathrm{d}^{-}$of pioglitazone based on an average daily food consumption of $5 \mathrm{~g}$ of chow per mouse. Of note, pioglitazone does not affect blood glucose levels in mice as determined in a set of pilot experiments using the identical treatment protocol in accordance with previous observations in nondiabetic mice (Shiomi et al., 2002).

Assessment of motor function and disease progression. The motor performance of all mice was assessed weekly with the paw grip endurance test (Weydt et al., 2003). Animals were placed individually on a meshed wire platform, which was then gently turned upside-down. The latency until a mouse let loose with both hind legs was monitored, with a cutoff time of $90 \mathrm{~s}$. Each mouse was given three consecutive trials, and the longest latency was recorded. As additional parameters, body weight, survival times, and time of motor dysfunction onset were monitored ( $n=8$ for wt; $n=13$ for wt-Pio; $n=10$ for SOD1; $n=7$ for SOD1-Pio). The body weight was expressed as percentage of the weight at the beginning of the experiment to account for absolute differences between individual mice. The onset of motor dysfunction was considered to be the first out of 3 consecutive paw grip endurance test days in which a mouse failed to reach the cutoff time.

Immunohistochemistry. Four to six mice per group were used for the analyses on the cellular and molecular levels. The mice were deeply anesthetized by isoflurane inhalation and killed by cervical dislocation. Two different dissection, fixation, and staining protocols were used. First, for bright-field motor neuron immunohistochemistry, the lumbar parts of the spinal cord were dissected out quickly and immersion fixed in Bouin Hollande fixative, containing $4 \%(\mathrm{w} / \mathrm{v})$ picric acid, 3.7\% (v/v) formalde- hyde, and 1\% (v/v) glacial acetic acid. The tissue was embedded in paraffin, cut with a microtome at $7 \mu \mathrm{m}$ thickness, and mounted on silanized glass slides. Sections were then stained for calcitonin gene-related peptide (CGRP) immunoreactivity essentially as described in detail previously (Schutz et al., 2004). For the quantification of motor neurons, CGRPpositive cell bodies were counted on six sections per animal and the mean number per section calculated. To avoid false double counting, the sections were $49 \mu \mathrm{m}$ apart from each other. Immunohistochemical detection of microglia was performed by staining with a rat monoclonal antibody against murine CD11b (diluted 1:250; catalog \#MCA711; Serotec, Düsseldorf, Germany) and visualized by using the avidin-biotin peroxidase complex method (ABC kit; Vector Laboratories, Burlingame, CA) with 3,3'-diaminobenzidine tetrahydrochloride as chromogen. For quantification, the microglia were subdivided into three activation states (resting, intermediate, activated) according to their morphological appearance and the number quantified per section.

Second, for the simultaneous fluorescent immunohistochemical detection of motor neurons and microglia, freshly dissected pieces of lumbar spinal cord were frozen quickly in isopentane at $-40^{\circ} \mathrm{C}$. Eight micrometer sections were cut with a cryostat and mounted on silanized glass slides. The slides were dried at room temperature overnight and fixed in $4 \%$ paraformaldehyde for $15 \mathrm{~min}$ at room temperature. Retrieval of antigen sites, blocking of endogenous peroxidase activity, and blocking of nonspecific binding sites was performed according to standard protocols. Double staining was performed by adding simultaneously both first antibodies followed by overnight incubation at $4^{\circ} \mathrm{C}$. Immunoreactions were visualized with goat secondary antibodies (cyanine 3-conjugated anti-rabbit, diluted 1:150; Alexa488-conjugated anti-rat, diluted 1:200; Jackson ImmunoResearch, West Grove, PA). Negative controls included omission of the primary and secondary antibodies.

Determination of muscle fiber diameter. Cryosections of $8 \mu \mathrm{m}$ thickness that underwent routine hematoxylin and eosin $(\mathrm{HE})$ staining were used to determine the muscle fiber diameters ( $n=3$ for wt; $n=4$ for wt-Pio; $n=4$ for SOD1; $n=5$ for SOD1-Pio). Using the standard method for myological diagnostics, the "lesser fiber diameter" was taken as described previously by others (Brooke and Engel, 1969). More than 100 fibers per muscle were measured in random fields of view under 20-fold primary magnification on a Nikon (Düsseldorf, Germany) H800 microscope with a CCD camera (DXP-9100P 3CCD color video; Sony, Tokyo, Japan) and using Lucia imaging software (LIM Laboratory Imaging; distributed by Nikon). The fiber measurements from each muscle section were pooled per group for statistical analysis.

Western blotting. Mouse spinal cord tissue ( $n=4$ for all groups) was homogenated in radioimmunoprecipitation assay buffer (1\% Triton, $1 \%$ sodium deoxycholate, $0.1 \%$ SDS, $150 \mathrm{~mm} \mathrm{NaCl}, 50 \mathrm{~mm}$ Tris-HCl, $\mathrm{pH} 7.2$ ) using an Ultraturrax T25 (Janke \& Kunkel, IKA-Labortechnik, Germany). For the analysis of iNOS and COX-2, $100 \mu \mathrm{g}$ of protein samples was separated in $10 \%$ SDS gels, transferred onto Immobilon-P polyvinylidene difluoride membranes, and stained with a polyclonal iNOS antibody at 1:500 dilution (rabbit polyclonal antibody to $\mathrm{C}$ terminus of murine iNOS; Santa Cruz Biotechology, Heidelberg, Germany) or a polyclonal COX-2 antibody at a 1:600 dilution (rabbit polyclonal antibody to synthetic peptide from murine COX-2; Cayman, Ann Arbor, $\mathrm{MI})$. The specificities of the iNOS and COX-2 antibodies have been confirmed by positive controls containing iNOS or COX-2 protein (data not shown). For the analysis of human and mouse SOD $1,2 \mu \mathrm{g}$ of protein samples was separated in 15\% SDS gels, transferred onto nitrocellulose membranes, and stained with a rabbit polyclonal anti-human SOD1 antibody at 1:5000 dilution (SOD-100; Stressgen, Victoria, British Colombia, Canada) or a rabbit polyclonal anti-mouse SOD1 antibody at 1:5000 dilution (SOD-101; Stressgen). The specificity of the SOD-100 antibody was confirmed by a negative (wild-type mouse brain total protein) control (data not shown). The SOD-101 antibody predominantly detected mouse SOD1 but in addition showed minimal cross-reactivity with human SOD1. The blots were incubated with horseradish peroxidasecoupled secondary antibody and developed using chemiluminescence (Amersham Biosciences, Freiburg, Germany). Afterward, the blots were stripped and stained with a monoclonal anti- $\beta$-actin antibody at 1:10,000 dilution (Sigma Aldrich, Taufkirchen, Germany). 
RNA preparation and reverse transcription-PCR. Spinal cord RNA was extracted using Trizol ( $n=5$ for each group) followed by reverse transcription-PCR (RT-PCR). The primers were the following: suppressor of cytokine signaling (SOCS)-1, forward, 5'-AGC-AGC-TCG-AAAAGG-CAG-TC-3' and reverse, 5'-ACA-CTC-ACT-TCC-GCA-CCTTC-3'; SOCS-3, forward, 5'-ACC-AGC-GCC-ACT-TCT-TCA-CG-3' and reverse, $5^{\prime}$-GTG-GAG-CAT-CAT-ACT-GAT-CC-3'; mouse SOD1, forward, 5'-GTC-CGT-CGG-CTT-CTC-GTC-T-3' and reverse, 5' CAC-AAC-TGG-TTC-ACC-GCT-TG-3'; human SOD1, forward, 5' TGG-TTT-GCG-TCG-TAG-TCT-CCT-3' and reverse, $5^{\prime}$-AAT-GCTTCC-CCA-CAC-CTT-CA-3'. Glyceraldehyde-3-phosphate dehydrogenase forward, 5' -TCA-CCA-GGG-CTG-CCA-TTT-GC-3' and reverse, 5' GAC-TCC-ACG-ACA-TAC-TCA-GC-3' were used as housekeeping control for SOCS- 1 and $3 ; \beta$-actin forward, $5^{\prime}$-CAC-AGC-TTC-TTT-GCAGCT-CCT-T-3' and reverse, 5'-TCA-GGA-TAC-CTC-TCT-TGC-TCTGG-3' were used as housekeeping control for mouse and human SOD1.

PCR conditions for SOCS PCR were 32 cycles of denaturation at $95^{\circ} \mathrm{C}$ for $30 \mathrm{~s}$, annealing at $63^{\circ} \mathrm{C}$ for $45 \mathrm{~s}$, and extension at $72^{\circ} \mathrm{C}$ for $45 \mathrm{~s}$ using a PX2 thermocycler (ThermoHybaid, Ulm, Germany). PCR products were separated by electrophoresis through $2 \%$ agarose containing $0.5 \mu \mathrm{g} / \mathrm{ml}$ ethidium bromide and imaged using an Alpha Inotech (Temecula, CA) imaging system.

The SOD1 PCRs were performed using a SYBR Green Jump Start Taq ready mix (Sigma Aldrich). Amplification conditions were 35 cycles of denaturation at $94^{\circ} \mathrm{C}$ for $15 \mathrm{~s}$, annealing at $62.5^{\circ} \mathrm{C}$, and extension at $72^{\circ} \mathrm{C}$ for $60 \mathrm{~s}$ using an Opticon real-time PCR detector (MJ Research/Bio-Rad, München, Germany). Fluorescent signals were normalized to baseline (minimum over all data) and a threshold cycle $\left(C_{\mathrm{T}}\right)$ determined within the exponential phase of the reaction. Each PCR was performed in triplicate and the mean $C_{\mathrm{T}}$ value determined.

Quantification and statistical analysis. Western blot and SOCS RTPCR experiments were quantified by determination of band intensities using ImageJ public domain software from the National Institutes of Health (http://rsb.info.nih.gov/ij/). The obtained data were analyzed by ANOVA followed by a Tukey's post hoc test. For the calculation of the relative abundancies of mouse and human SOD1 transcripts, the differences in $C_{\mathrm{T}}$ between $\beta$-actin and SOD1 were determined and expressed as $x$-fold difference from $\beta$-actin expression using the following equation: $2^{-\Delta C_{T}}$. The obtained data were analyzed by ANOVA followed by a Tukey's post hoc test. For statistical analysis of muscle fiber diameters, Kruskal-Wallis one-way ANOVA on ranks, followed by testing with Dunn's multiple comparisons versus control group method, was used. All other statistical analyses were performed by one-way ANOVA followed by Bonferroni's post hoc test (for body weight, paw grip endurance test, and motor neuron cell count) or by Cox's $F$ test (survival analysis and onset of motor dysfunction).

\section{Results \\ Oral pioglitazone treatment delays disease progression and improves clinical symptoms in SOD1-G93A mice}

Treatment of SOD1-G93A mice with Pio was initiated at day 57 of life, because inflammation is an early event during disease progression in SOD1-G93A mice and significantly precedes clinical symptoms (Hensley et al., 2002; Yoshihara et al., 2002). Thus, reducing microglial activation and release of potentially harmful inflammatory molecules seemed to be desirable from a very early time point on. Pio treatment resulted in an extended life expectancy compared with nontreated transgenic mice (Fig. 1a). The mean survival was increased by $10 \mathrm{~d}$ from $123 \pm 7 \mathrm{~d}$ in nontreated mice $(n=10)$ to $133 \pm 6 \mathrm{~d}$ in Pio-treated mice $(n=7 ; p=0.03)$. Pio treatment also prevented SOD1-G93A mice from early weight loss (Fig. 1b). Whereas SOD1-G93A mice had already reached their maximum body weight at $70 \mathrm{~d}$ of life and started to lose weight from day 98 on, Pio-treated SOD1-G93A mice gained initially weight comparable to nontreated $(n=8)$ and treated $(n=13)$ wild-type mice and started to fall at $105 \mathrm{~d}$. Thus, Pio treatment significantly increased body weight compared with nontreated SOD1-G93A mice from day 77 of life until the end of the study. Importantly, chronic progressive motor dysfunction was delayed by Pio treatment. First, the probability of motor deficit onset (Fig. 1c) was delayed by $10 \mathrm{~d}$ from $100 \pm 8 \mathrm{~d}$ in nontreated to $110 \pm 11 \mathrm{~d}$ in Pio-treated SOD1-G93A mice $(p=$ 0.02 ). Second, the decline of motor performance was attenuated by $\sim 14$ d in Pio-treated mice compared with nontreated SOD1G93A mice (Fig. 1d).

\section{Pioglitazone protects from motor neuron loss and muscular atrophy}

Clinical symptoms such as muscle wasting and paresis occur subsequently to the loss of motor neurons. To determine whether Pio treatment protects not only from clinical disease progression but also from the causative ongoing motor neuron loss, we evaluated motor neuron numbers in spinal cord sections. At day 56 of life, before onset of treatment, wild-type $(n=4)$ and SOD1G93A ( $n=6)$ mice had similar motor neuron numbers (data not shown). At $90 \mathrm{~d}$ of life (i.e., at the onset of clinical symptoms), SOD1-G93A mice $(n=6)$ already showed a $30 \%$ loss of motor neurons (Fig. 2a). Although Pio treatment did not affect motor neuron numbers of wild-type mice $(n=5)$, it completely protected SOD1-G93A mice $(n=6)$ from motor neuron loss up to this age. Qualitative analysis of the motor neuron field at day 90 of life revealed no morphological differences between Pio-treated and nontreated wild-type mice (Fig. 2b). In contrast, SOD1G93A mice showed typical histopathological changes including intracellular vacuoles in motor neurons and spherical axonal enlargements. Importantly, Pio treatment almost completely reduced these signs of neuron degeneration in SOD1-G93A mice.

To determine the functional status of the Pio-preserved motor neurons, we assessed muscle fiber integrity of the quadriceps muscle in the hind leg, an innervation target of the spinal motor neurons counted. The median fiber diameters were $36.6 \mu \mathrm{m}$ in wild-type ( $n=3$; 376 fibers $)$ and $36.9 \mu \mathrm{m}$ in Pio-treated wild-type ( $n=4 ; 472$ fibers) mice (Fig. $2 a$ ). Concomitantly to motor neuron loss, SOD1-G93A mice ( $n=4 ; 525$ fibers) showed a reduction of the median fiber diameter to $25.4 \mu \mathrm{m}$. Importantly, SOD1-G93A mice treated with Pio ( $n=5 ; 574$ fibers) showed a median fiber diameter of $35.3 \mu \mathrm{m}$, suggesting not only structural but also functional protection of ventral horn motor neurons.

\section{Pioglitazone reduces microglia activation at sites of neurodegeneration, blocks activation of proinflammatory enzymes, and enhances expression of anti-inflammatory genes} PPAR $\gamma$ ligands suppress microglial activation, thereby protecting neurons from inflammation-mediated cell death (Heneka et al., 1999; Combs et al., 2000). Therefore, spinal cord sections were colabeled for CGRP and CD11b to visualize motor neurons and microglia, respectively, allowing an assessment of whether Pio treatment reduced inflammatory events at sites of neurodegeneration. A large number of microglia were found in close vicinity to motor neurons in 90-d-old SOD1-G93A mice (Fig. 3a). Three different states of microglial activation, ranging from resting to intermediate and fully activated, were determined and then quantified. Whereas arborized and resting microglia comprised the vast majority in Pio-treated $(n=4)$ and nontreated $(n=4)$ wild-type mice, the majority of microglia in SOD1-G93A mice $(n=5)$ belonged to the intermediate or activated type. Notably, treatment with Pio reduced the number of fully activated microglia in SOD1-G93A mice $(n=5)$ by $\sim 50 \%$.

Coinduction of COX-2 and iNOS were described in several 
a

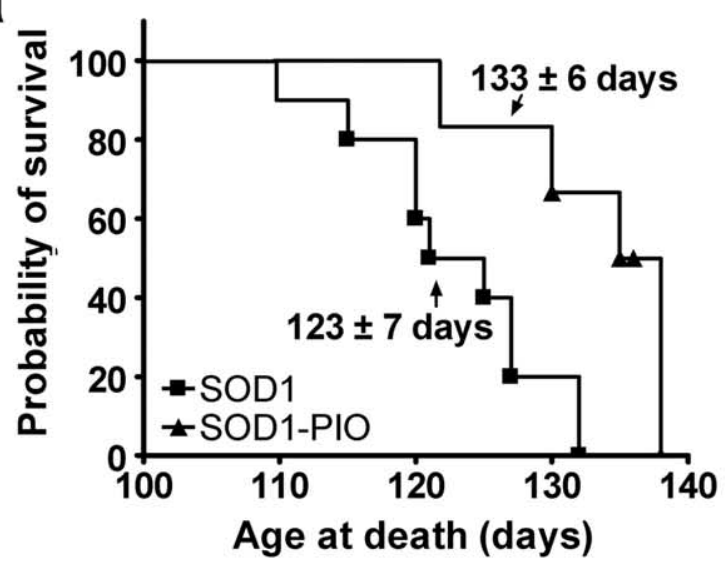

b

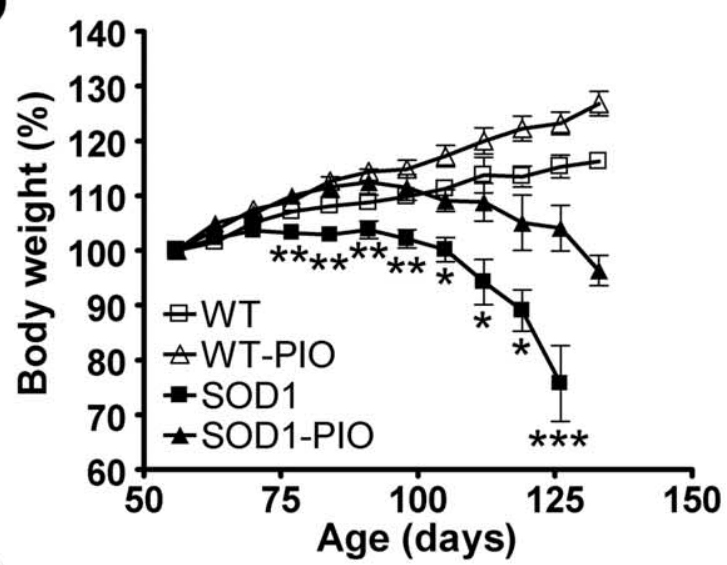

C

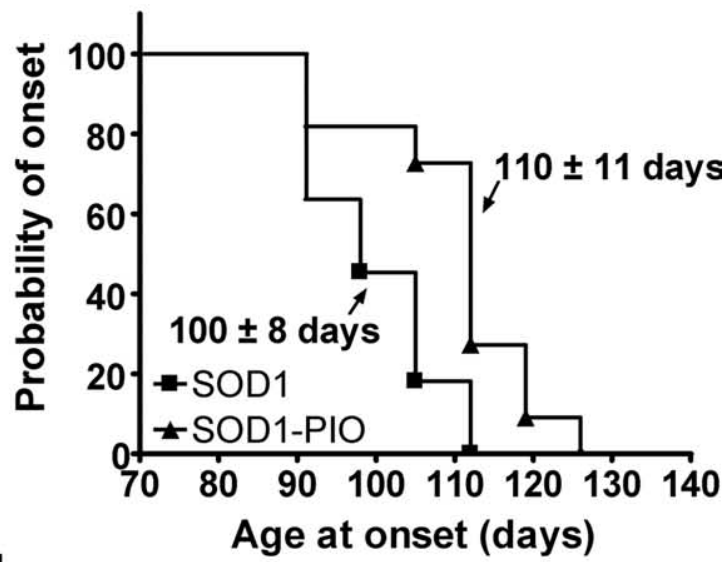

d

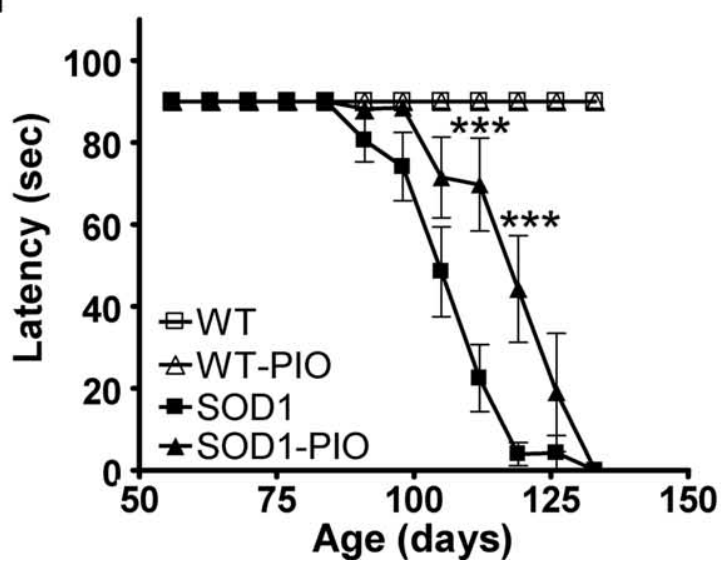

a
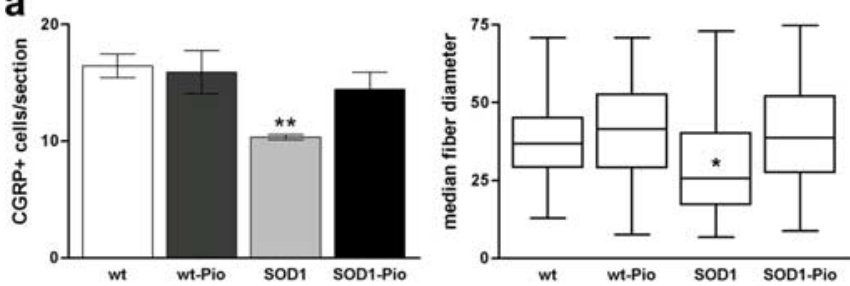

b

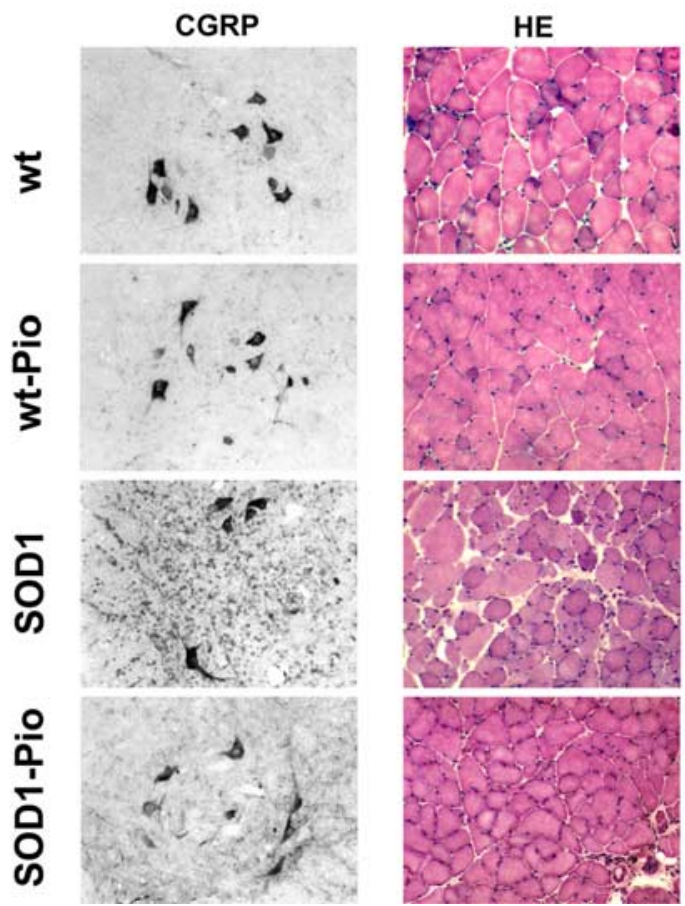

Figure 2. Effect of pioglitazone treatment on motor neuron degeneration and muscle fiber morphology. $\boldsymbol{a}$, CGRP-positive motor neuron numbers in the lumbar spinal cord ( $n=5$ for wild-type group; $n=6$ for SOD1 groups) and median fiber diameters in the quadriceps muscle ( $n=3$ for wt; $n=4$ for wt-Pio; $n=4$ for SOD1; $n=5$ for SOD1-Pio) at day 90 of life. ${ }^{*} p<$ 0.05 and ${ }^{* *} p<0.01$ compared with Pio-treated SOD1 mice. Error bars represent SEM (CGRP ${ }^{+}$ cells) or SD (median fiber diameter). $\boldsymbol{b}$, Evaluation of the spinal cord motor neuron area by CGRP immunohistochemistry and muscle fiber morphology by histological HE stain.

neurodegenerative disorders including ALS, as well as in the SOD1-G93A model used in this study (Almer et al., 1999, 2001; Sasaki et al., 2001). Western blot analysis of lumbar spinal cord lysates from 90-d-old mice confirmed COX-2 expression in wildtype mice $(n=4)$ and revealed that SOD1-G93A mice $(n=4)$ showed elevated COX-2 levels (Fig. $3 b$ ). In contrast, iNOS was hardly detectable in wild-type but strongly expressed by SOD1G93A mice (Fig. $3 b$ ). In both cases, Pio treatment significantly decreased COX-2 and iNOS expression in SOD1-G93A mice $(n=4)$. Notably, this reduction was paralleled by a marked transcriptional upregulation of anti-inflammatory SOCS-1 and SOCS-3 genes (Fig. $3 c$ ) in both Pio-treated groups $(n=5$ for all groups).

Figure 1. Effects of pioglitazone treatment on survival, body weight, and motor functions in SOD1-G93A mice. $\boldsymbol{a}$, Probability of survival in nontreated (SOD1; $n=10$ ) compared with Piotreated (SOD1-Pio; $n=7$ ) mice. Data are expressed as mean \pm SEM. $\boldsymbol{b}$, Time course of changes in body weight of nontreated (wt; $n=8$ ) and Pio-treated (wt-Pio; $n=13$ ) wild-type mice compared with their respective SOD1 and S0D1-Pio mice. ${ }^{*} p<0.05,{ }^{* *} p<0.01$, and ${ }^{* * *} p<$ 0.001 compared with SOD1-Pio. c, Probability of onset of motor dysfunctions in nontreated (SOD1) compared with Pio-treated (SOD1-Pio) mice. $\boldsymbol{d}$, Time course of motor performance in the paw grip endurance test. ${ }^{* * *} p<0.001$ compared with SOD1 mice. 
a
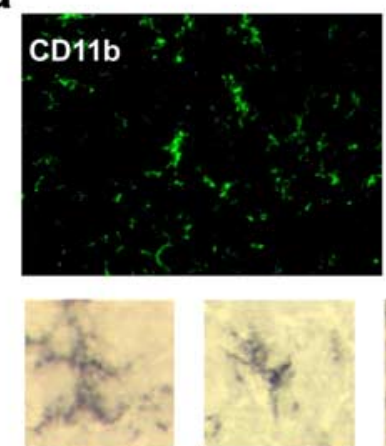

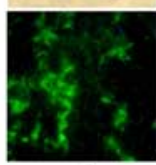

I

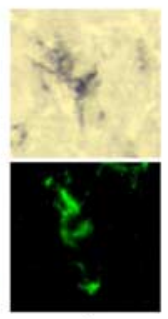

II
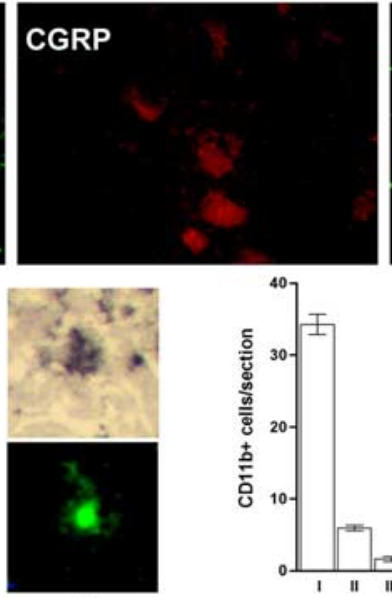

III

b

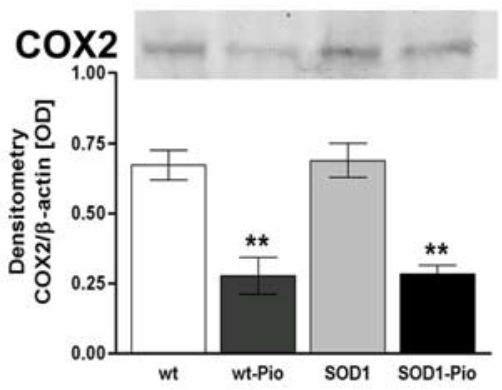

C
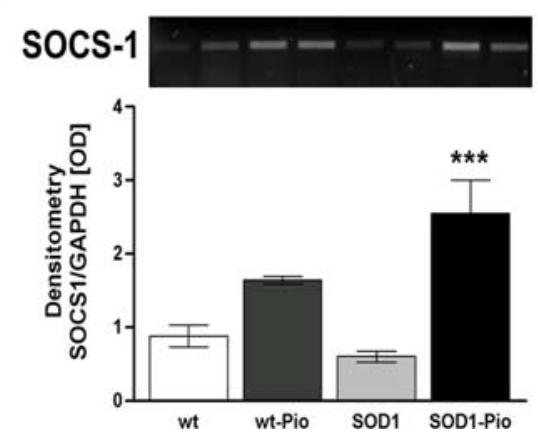
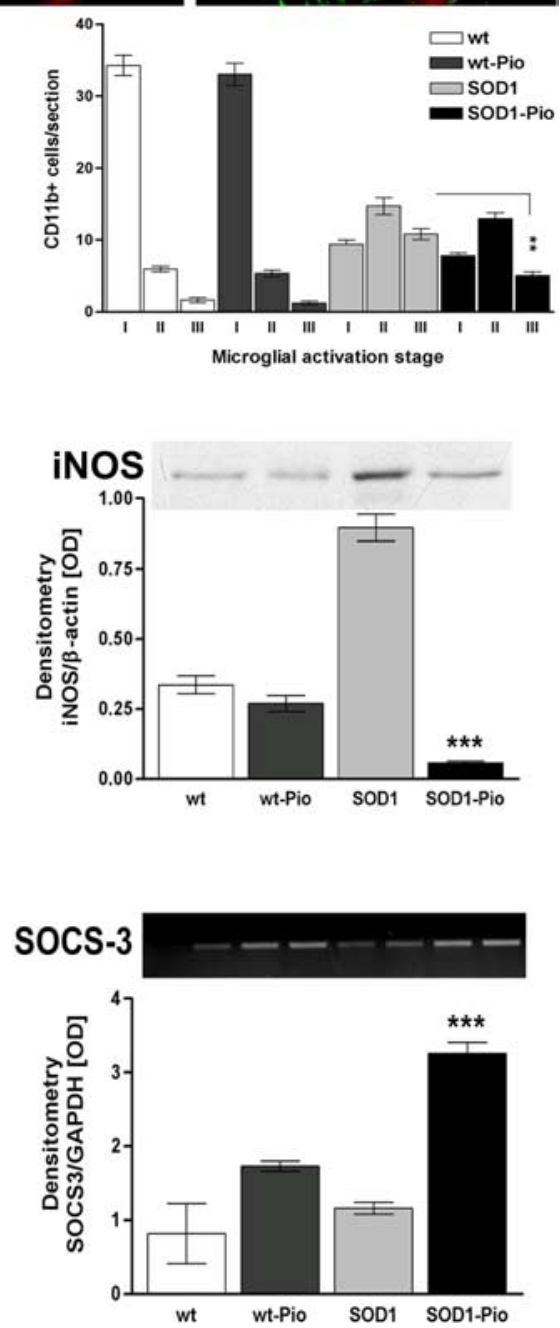

Figure 3. Effect of pioglitazone treatment on the activation of astroglia and inflammation markers. $\boldsymbol{a}$, Immunofluorescence colabeling of CD11b (green) and CGRP (red) in the spinal cord motor neuron area at day 90 of life (top). Examples for the classification of microglia activation states by bright-field (blue/black reaction products) and green fluorescent CD11b immunohistochemistry (bottom left) are shown. Quantification of microglia at day 90 of life (bottom right; $n=4$ for wt and wt-Pio; $n=$ 5 for SOD1 and SOD1-Pio) and of COX-2 and iNOS Western blots ( $n=4$ for all groups) from spinal cord samples derived from 90-d-old mice $(\boldsymbol{b})$ are shown. ${ }^{* *} p<0.01$ and ${ }^{* * *} p<0.001$ compared with the respective nontreated group. $\boldsymbol{c}$, Quantification of SOCS-1 and SOCS-3 mRNA levels in the spinal cord at day 90 of life ( $n=5$ for all groups). Representative gels of two animals per group are shown. ${ }^{* * *} p<0.001$ compared with nontreated SOD1 mice. Error bars represent SEM

Pioglitazone treatment does not alter expression levels of endogenous and transgenic SOD1

Because the expression level of the mutant SOD1 transgene affects the course of disease in SOD1-G93A mice and the beneficial effect of Pio treatment could be the consequence of an altered expression of either endogenous mouse or transgenic human SOD1, we determined SOD1 gene expression levels in our mice. Spinal cord samples from 90 -d-old mice (i.e., $33 \mathrm{~d}$ after initiation of Pio treatment) were processed for total RNA and protein, and both mouse and human SOD1 expression levels were determined using quantitative RT-PCR and Western blotting. As shown in Figure 4, neither mouse SOD1 mRNA (Fig. $4 a$ ) or protein (Fig. 4c) levels nor human SOD1 mRNA (Fig. $4 b$ ) or protein (Fig. $4 d$ ) levels were significantly affected by Pio treatment ( $n=4$ for each group).

\section{Discussion}

ALS is a fatal neurodegenerative disease without curative treatment options to date. Progressive neuron cell death of cortical and spinal motor neurons causes corticospinal tract signs, wasting and atrophy of targeted muscles, and subsequent paresis. Several pathological factors including excitotoxic, apoptotic, and metabolic mechanisms have been implied in ALS pathogenesis and proposed as therapeutic targets (Talbot, 2002). More recently, an inflammatory component of the disease has been described (McGeer and McGeer, 2002), and potentially detrimental mediators and systems of inflammation were discovered at sites of degenerating motor neurons (Weydt et al., 2002).

\section{PPAR $\gamma$ and neuroinflammation}

Although neuroinflammation may at first arise as a response to motor neuron destruction, the ongoing presence of proinflammatory mediators and an inflammation-evoked release of free radicals may significantly contribute to the development and progression of ALS. Originally developed as oral antidiabetics, agonists of PPAR $\gamma$ have been found to exert potent anti-inflammatory effects in several models of neuroinflammation (Landreth and Heneka, 2001; Feinstein, 2003). Because PPAR $\gamma$-mediated reduction of inflammation was neuroprotective, we hypothesized that SOD1-G93A transgenic mice would benefit from chronic treatment with a PPAR $\gamma$ agonist. Within the thiazolidinedione class of PPAR $\gamma$ agonists, Pio is the only substance that penetrates the blood-brain barrier to a significant extent (Maeshiba et al., 1997) and has therefore been chosen for treatment experiments. Our results strongly suggest that Pio-mediated suppression of inflammation may offer a new therapeutic avenue in ALS treatment, as supported by previous findings in animal models of multiple sclerosis (Niino et al., 2001; Feinstein et al., 2002; Natarajan et al., 2003), Parkinson's disease (Breidert et al., 2002), and stroke (Sundararajan et al., 2005).

\section{PPAR $\gamma$ and microglial activation}

Immunohistochemical determination of microglia showed that activated microglial cells were found in close contact to degenerating motor neurons. Here, a wide spectrum of microglial cells including arborized and presumably resting cells to fully acti- 

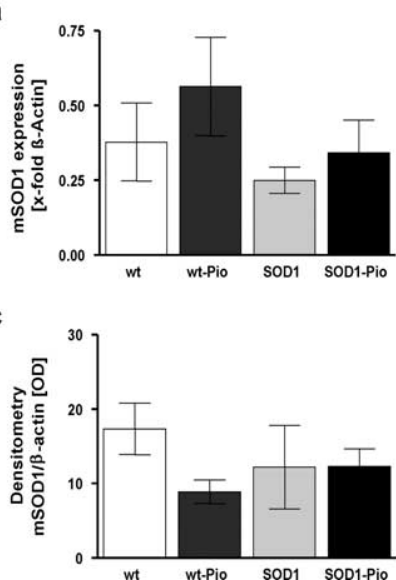

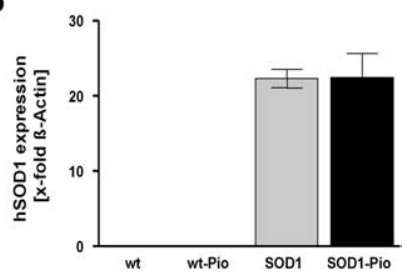

d

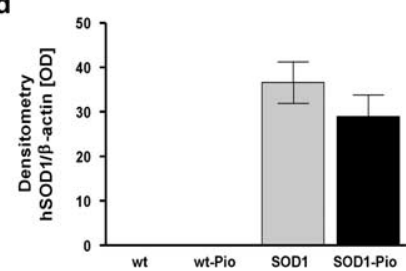

Figure 4. Effect of pioglitazone treatment on the expression levels of endogenous and transgenic SOD1. $\boldsymbol{a}-\boldsymbol{d}$, Quantification of mouse SOD1 (a) and human SOD1 (b) MRNA expression levels, and of mouse SOD1 (c) and human SOD1 (d) protein levels in the spinal cord at day 90 of life ( $n=4$ for all groups). Note the variations in mouse SOD1 expression levels between the groups in $\boldsymbol{a}$ and $\boldsymbol{c}$. All data are represented as mean \pm SEM.

vated microglia were detectable in the ventral horn of wild-type and SOD1-G93A mice. Whereas the vast majority of microglial cells belonged to the arborized and resting type in wild-type mice, a marked shift toward intermediate or fully activated microglial cells was detectable in SOD1-G93A animals. Again, Pio treatment reduced the number of fully activated microglia cells by $\sim 50 \%$. This is in accordance with previous findings by Combs et al. (2000) who found that several PPAR $\gamma$ agonists reduced microglia activation and thereby protected neurons.

\section{PPAR $\boldsymbol{\gamma}$-mediated inhibition of inflammatory mediators}

We found a marked reduction in the expression of COX-2 and iNOS, two major proinflammatory enzymes, after Pio treatment. Coinduction of both enzymes by several factors including glutamate release and secretion of proinflammatory cytokines may be caused by similar or identical stimulators (O’Banion, 1999), because the COX-2 and iNOS promoters share several binding sites for signal transduction factors involved in inflammatory signal cascades (Xie et al., 1993; Nathan and Xie, 1994). Apart from the detrimental action of either iNOS-derived excess NO or COX-2generated proinflammatory prostanoids, the dual inhibition of both enzymes observed in response to Pio treatment may be advantageous, because both pathways mutually increase their pathogenicity. Thus, NO may increase the catalytic activity of COX-2, thereby increasing the production of proinflammatory prostanoids (Nogawa et al., 1998). Alternatively, NO may react with radical oxygen species formed by the peroxidase step of the conversion of prostaglandin $\mathrm{g} 2$ to prostaglandin $\mathrm{h} 2$, yielding even more toxic and tissue damaging radicals such as peroxynitrite.

\section{PPAR $\boldsymbol{\gamma}$-mediated activation of anti-inflammatory genes}

Several PPAR $\gamma$-dependent and -independent anti-inflammatory actions of the TZD class of drugs have been described, and suppression of inflammation may be achieved not at a single but at multiple levels including direct regulation of promotor activity, sequestering of coactivator molecules, and inhibition of nuclear factor $\kappa \mathrm{B}$ signaling (for review, see Landreth and Heneka, 2001; Feinstein, 2003). Interestingly, SOCS-1 and SOCS-3 have been reported to increase in response to TZDs in microglia and astrocytes in vitro, which in turn inhibit Janus kinase-signal transducer and activator of transcription (JAK-
STAT) inflammatory signal transduction (Park et al., 2003). The latter signal transduction pathway is also involved in the iNOS and COX-2 gene regulation after inflammatory stimulation. Because the ability of SOCS- 1 and SOCS- 3 to suppress cytokine stimulation has also been confirmed by in vivo experiments using knock-out mice (Shouda et al., 2001; Suzuki et al., 2001), it seems likely that upregulation of SOCS-1 and SOCS-3 levels in response to Pio treatment reflects one mechanism of the anti-inflammatory effect observed and antagonizing the JAK-STAT pathway contributes to the observed suppression of iNOS and COX-2 expression.

\section{Alternative actions of pioglitazone}

The principal clinical usage of PPAR $\gamma$ agonists is for treatment of type II diabetes. The drugs act to enhance insulin sensitivity and normalize blood glucose levels (Patsouris et al., 2004; YkiJarvinen, 2004). It therefore seems possible that the reported salutary effects of PPAR $\gamma$ in enhancing muscle strength and preserving neuronal integrity and function might also arise from improved glucose utilization in the spinal cord and the muscle in addition to the anti-inflammatory actions of these drugs (Watson and Craft, 2003).

It has been shown recently that PPAR $\gamma$ agonist treatment leads to an upregulation of $\mathrm{Cu} / \mathrm{Zn}-\mathrm{SOD} 1$ expression in a rat model of ischemia (Shimazu et al., 2005), suggesting that enhanced SOD1 levels may be protective by reducing oxidative stress. Because we found no changes in the expression levels of neither mouse nor human SOD1 in our mice, we can rule out that the reported effects of chronic Pio treatment result from altered endogenous SOD1 or transgenic SOD1-G93A expression levels.

\section{Antiinflammatory treatment strategies in ALS}

The hypothesis that neuroinflammation, once it has been initiated by degenerating neurons, significantly contributes to the progression of motor neuron death in ALS has been supported by studies on SOD1 transgenic mice reporting protective effects of cyclooxygenase inhibitors (Drachman et al., 2002; Pompl et al., 2003; Azari et al., 2005). However, important issues regarding human bioavailability within the brain and spinal cord regions concerned, time period needed for effective treatment, as well as the time point of treatment onset necessary for protection need to be answered. Until these questions have not been fully addressed, any clinical trials will have to be interpreted with caution, regardless of their positive or negative outcome.

The present experiments using an early anti-inflammatory treatment strategy initiated well before the first onset of clinical symptoms does not allow us to conclude that patients suffering from sporadic ALS will benefit from PPAR $\gamma$-agonist treatment if initiated after clinical onset of disease. However, it seems possible that in the case of familiar ALS, family members with an inherited ALS risk, which can be diagnosed before the appearance of clinical symptoms, may benefit from prophylactic PPAR $\gamma$-agonist medication. Because the drugs concerned have been proven to be safe and are already in clinical use for NIDDM treatment, they would be available readily for clinical trials in human ALS.

\section{References}

Akiyama H, Barger S, Barnum S, Bradt B, Bauer J, Cole GM, Cooper NR, Eikelenboom P, Emmerling M, Fiebich BL, Finch CE, Frautschy S, Griffin WS, Hampel H, Hull M, Landreth G, Lue L, Mrak R, Mackenzie IR, McGeer PL, et al. (2000) Inflammation and Alzheimer's disease. Neurobiol Aging 21:383-421. 
Almer G, Vukosavic S, Romero N, Przedborski S (1999) Inducible nitric oxide synthase up-regulation in a transgenic mouse model of familial amyotrophic lateral sclerosis. J Neurochem 72:2415-2425.

Almer G, Guegan C, Teismann P, Naini A, Rosoklija G, Hays AP, Chen C, Przedborski S (2001) Increased expression of the pro-inflammatory enzyme cyclooxygenase-2 in amyotrophic lateral sclerosis. Ann Neurol 49:176-185.

Azari MF, Profyris C, Le Grande MR, Lopes EC, Hirst J, Petratos S, Cheema SS (2005) Effects of intraperitoneal injection of Rofecoxib in a mouse model of ALS. Eur J Neurol 12:357-364.

Barbeito LH, Pehar M, Cassina P, Vargas MR, Peluffo H, Viera L, Estevez AG, Beckman JS (2004) A role for astrocytes in motor neuron loss in amyotrophic lateral sclerosis. Brain Res Brain Res Rev 47:263-274.

Berger J, Moller DE (2002) The mechanisms of action of PPARs. Annu Rev Med 53:409-435.

Blanquart C, Barbier O, Fruchart JC, Staels B, Glineur C (2003) Peroxisome proliferator-activated receptors: regulation of transcriptional activities and roles in inflammation. J Steroid Biochem Mol Biol 85:267-273.

Breidert T, Callebert J, Heneka MT, Landreth G, Launay JM, Hirsch EC (2002) Protective action of the peroxisome proliferator-activated receptor-gamma agonist pioglitazone in a mouse model of Parkinson's disease. J Neurochem 82:615-624.

Brooke MH, Engel WK (1969) The histographic analysis of human muscle biopsies with regard to fiber types. 2. Diseases of the upper and lower motor neuron. Neurology 19:378-393.

Combs CK, Johnson DE, Karlo JC, Cannady SB, Landreth GE (2000) Inflammatory mechanisms in Alzheimer's disease: inhibition of $\beta$-amyloidstimulated proinflammatory responses and neurotoxicity by PPAR $\gamma$ agonists. J Neurosci 20:558-567.

Daynes RA, Jones DC (2002) Emerging roles of PPARs in inflammation and immunity. Nat Rev Immunol 2:748-759.

Drachman DB, Frank K, Dykes-Hoberg M, Teismann P, Almer G, Przedborski S, Rothstein JD (2002) Cyclooxygenase 2 inhibition protects motor neurons and prolongs survival in a transgenic mouse model of ALS. Ann Neurol 52:771-778.

Feinstein DL (2003) Therapeutic potential of peroxisome proliferatoractivated receptor agonists for neurological disease. Diabetes Technol Ther 5:67-73.

Feinstein DL, Galea E, Gavrilyuk V, Brosnan CF, Whitacre CC, DumitrescuOzimek L, Landreth GE, Pershadsingh HA, Weinberg G, Heneka MT (2002) Peroxisome proliferator-activated receptor-gamma agonists prevent experimental autoimmune encephalomyelitis. Ann Neurol 51: 694-702.

Grommes C, Landreth GE, Heneka MT (2004) Antineoplastic effects of peroxisome proliferator-activated receptor gamma agonists. Lancet Oncol 5:419-429.

Gurney ME, Pu H, Chiu AY, Dal Canto MC, Polchow CY, Alexander DD, Caliendo J, Hentati A, Kwon YW, Deng HX (1994) Motor neuron degeneration in mice that express a human $\mathrm{Cu}, \mathrm{Zn}$ superoxide dismutase mutation. Science 264:1772-1775.

Heiman-Patterson TD, Deitch JS, Blankenhorn E, Erwin K, Perreault MJ, Alexander B, Alexander GM (2003) Background and gender effects on survival in the SOD1(G93A) transgenic mouse model of ALS. Amyotroph Lateral Scler Other Motor Neuron Disord 4 [Suppl 1]:118.

Heneka MT, Feinstein DL, Galea E, Gleichmann M, Wullner U, Klockgether $\mathrm{T}$ (1999) Peroxisome proliferator-activated receptor gamma agonists protect cerebellar granule cells from cytokine-induced apoptotic cell death by inhibition of inducible nitric oxide synthase. J Neuroimmunol 100:156-168.

Heneka MT, Klockgether T, Feinstein DL (2000) Peroxisome proliferatoractivated receptor- $\gamma$ ligands reduce neuronal inducible nitric oxide synthase expression and cell death in vivo. J Neurosci 20:6862-6867.

Hensley K, Floyd RA, Gordon B, Mou S, Pye QN, Stewart C, West M, Williamson K (2002) Temporal patterns of cytokine and apoptosis-related gene expression in spinal cords of the G93A-SOD1 mouse model of amyotrophic lateral sclerosis. J Neurochem 82:365-374.

In t'Veld BA, Ruitenberg A, Hofman A, Launer LJ, van Duijn CM, Stijnen T, Breteler MM, Stricker BH (2001) Nonsteroidal antiinflammatory drugs and the risk of Alzheimer's disease. N Engl J Med 345:1515-1521.
Kunst CB (2004) Complex genetics of amyotrophic lateral sclerosis. Am J Hum Genet 75:933-947.

Landreth GE, Heneka MT (2001) Anti-inflammatory actions of peroxisome proliferator-activated receptor gamma agonists in Alzheimer's disease. Neurobiol Aging 22:937-944.

Lim GP, Yang F, Chu T, Chen P, Beech W, Teter B, Tran T, Ubeda O, Ashe KH, Frautschy SA, Cole GM (2000) Ibuprofen suppresses plaque pathology and inflammation in a mouse model for Alzheimer's disease. J Neurosci 20:5709-5714.

Maeshiba Y, Kiyota Y, Yamashita K, Yoshimura Y, Motohashi M, Tanayama S (1997) Disposition of the new antidiabetic agent pioglitazone in rats, dogs, and monkeys. Arzneimittelforschung 47:29-35.

McGeer PL, McGeer EG (2002) Inflammatory processes in amyotrophic lateral sclerosis. Muscle Nerve 26:459-470.

Natarajan C, Muthian G, Barak Y, Evans RM, Bright JJ (2003) Peroxisome proliferator-activated receptor-gamma-deficient heterozygous mice develop an exacerbated neural antigen-induced Thl response and experimental allergic encephalomyelitis. J Immunol 171:5743-5750.

Nathan C, Xie QW (1994) Regulation of biosynthesis of nitric oxide. J Biol Chem 269:13725-13728.

Niino M, Iwabuchi K, Kikuchi S, Ato M, Morohashi T, Ogata A, Tashiro K, Onoe K (2001) Amelioration of experimental autoimmune encephalomyelitis in C57BL/6 mice by an agonist of peroxisome proliferatoractivated receptor-gamma. J Neuroimmunol 116:40-48.

Nogawa S, Forster C, Zhang F, Nagayama M, Ross ME, Iadecola C (1998) Interaction between inducible nitric oxide synthase and cyclooxygenase-2 after cerebral ischemia. Proc Natl Acad Sci USA 95: $10966-10971$.

O’Banion MK (1999) Cyclooxygenase-2: molecular biology, pharmacology, and neurobiology. Crit Rev Neurobiol 13:45-82.

Park EJ, Park SY, Joe EH, Jou I (2003) 15d-PGJ2 and rosiglitazone suppress Janus kinase-STAT inflammatory signaling through induction of suppressor of cytokine signaling 1 (SOCS1) and SOCS3 in glia. J Biol Chem 278:14747-14752.

Patsouris D, Muller M, Kersten S (2004) Peroxisome proliferator activated receptor ligands for the treatment of insulin resistance. Curr Opin Investig Drugs 5:1045-1050.

Phul RK, Shaw PJ, Ince PG, Smith ME (2000) Expression of nitric oxide synthase isoforms in spinal cord in amyotrophic lateral sclerosis. Amyotroph Lateral Scler Other Motor Neuron Disord 1:259-267.

Pompl PN, Ho L, Bianchi M, McManus T, Qin W, Pasinetti GM (2003) A therapeutic role for cyclooxygenase-2 inhibitors in a transgenic mouse model of amyotrophic lateral sclerosis. FASEB J 17:725-727.

Sasaki S, Warita H, Abe K, Iwata M (2001) Inducible nitric oxide synthase (iNOS) and nitrotyrosine immunoreactivity in the spinal cords of transgenic mice with a G93A mutant SOD1 gene. J Neuropathol Exp Neurol 60:839-846.

Schutz B, Mauer D, Salmon AM, Changeux JP, Zimmer A (2004) Analysis of the cellular expression pattern of beta-CGRP in alpha-CGRP-deficient mice. J Comp Neurol 476:32-43.

Shimazu T, Inoue I, Araki N, Asano Y, Sawada M, Furuya D, Nagoya H, Greenberg JH (2005) A peroxisome proliferator-activated receptorgamma agonist reduces infarct size in transient but not in permanent ischemia. Stroke 36:353-359.

Shiomi T, Tsutsui H, Hayashidani S, Suematsu N, Ikeuchi M, Wen J, Ishibashi M, Kubota T, Egashira K, Takeshita A (2002) Pioglitazone, a peroxisome proliferator-activated receptor-gamma agonist, attenuates left ventricular remodeling and failure after experimental myocardial infarction. Circulation 106:3126-3132.

Shouda T, Yoshida T, Hanada T, Wakioka T, Oishi M, Miyoshi K, Komiya S, Kosai K, Hanakawa Y, Hashimoto K, Nagata K, Yoshimura A (2001) Induction of the cytokine signal regulator SOCS3/CIS3 as a therapeutic strategy for treating inflammatory arthritis. J Clin Invest 108:1781-1788.

Sundararajan S, Gamboa JL, Victor NA, Wanderi EW, Lust WD, Landreth GE (2005) Peroxisome proliferator-activated receptor-gamma ligands reduce inflammation and infarction size in transient focal ischemia. Neuroscience 130:685-696.

Suzuki A, Hanada T, Mitsuyama K, Yoshida T, Kamizono S, Hoshino T, Kubo M, Yamashita A, Okabe M, Takeda K, Akira S, Matsumoto S, Toyonaga A, 
Sata M, Yoshimura A (2001) CIS3/SOCS3/SSI3 plays a negative regulatory role in STAT3 activation and intestinal inflammation. J Exp Med 193:471-481.

Talbot K (2002) Motor neurone disease. Postgrad Med J 78:513-519.

Watson GS, Craft S (2003) The role of insulin resistance in the pathogenesis of Alzheimer's disease: implications for treatment. CNS Drugs 17:27-45.

Weydt P, Weiss MD, Moller T, Carter GT (2002) Neuro-inflammation as a therapeutic target in amyotrophic lateral sclerosis. Curr Opin Investig Drugs 3:1720-1724.

Weydt P, Hong SY, Kliot M, Moller T (2003) Assessing disease onset and progression in the SOD1 mouse model of ALS. NeuroReport 14:1051-1054.
Xie W, Merrill JR, Bradshaw WS, Simmons DL (1993) Structural determination and promoter analysis of the chicken mitogen-inducible prostaglandin $\mathrm{G} / \mathrm{H}$ synthase gene and genetic mapping of the murine homolog. Arch Biochem Biophys 300:247-252.

Yasojima K, Tourtellotte WW, McGeer EG, McGeer PL (2001) Marked increase in cyclooxygenase-2 in ALS spinal cord: implications for therapy. Neurology 57:952-956.

Yki-Jarvinen H (2004) Thiazolidinediones. N Engl J Med 351:1106-1118. Yoshihara T, Ishigaki S, Yamamoto M, Liang Y, Niwa J, Takeuchi H, Doyu M, Sobue G (2002) Differential expression of inflammation- and apoptosis-related genes in spinal cords of a mutant SOD1 transgenic mouse model of familial amyotrophic lateral sclerosis. J Neurochem 80: $158-167$. 